\title{
LA NECESARIA COOPERACION ENTRE LOS SISTEMAS DE JUSTICIA Y ASISTENCIAL EN EL TRATAMIENTO DE LA VIOLENCIA.
}

JOAQUÍN GIMÉNEZ GARCÍA

Magistrado Sala Segunda del Tribunal Supremo.

\section{LA JUSTICIA, EL JUEZ Y EL SERVICIO PÚBLICO.}

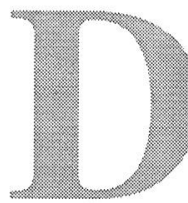

e entre las diversas aproximaciones o enfoques que pueden efectuarse en relación al término "justicia", me voy a referir a tres que tienen una especial significación con el título de la ponencia, y que cuentan con un específico reconocimiento constitucional.

El art. 1 de la Constitución Española se refiere a la justicia como un valor superior del Ordenamiento Jurídico, ya antes, en el Preámbulo se le cita como un fin a establecer.

En el art. 117, que inicia el Título VI, se habla de la Justicia como Poder Judicial, es decir, como uno de los tres poderes del Estado; finalmente, en el propio art. $117-1^{\circ}$, y más específicamente en el art. 149-5 aparece el término Administración de Justicia.

Hay pues una triple referencia a la Justicia en la Constitución como Valor - valor superior-, como Poder del Estado y, finalmente, como Administración, en referencia al Servicio Público que presta.

Como valor superior supone el explícito reconocimiento de la dimensión ética que tiene el Derecho, que debe ser algo diferente a una mera codificación de normas, la justicia como valor supone reconocer la permanente vocación del derecho a alcanzarla, en un permanente cuestionamiento y dinamismo, porque dinámica es la sociedad. En este sentido, se refería Aranguren retomando una clásica expresión, “...la justicia es la lucha por la justicia...".

Como Poder, la justicia nos reenvía al sistema judicial, centrado en la figura del Juez, ya no "...boca que pronuncia las palabras de la Ley...", en la conocida frase de Montesquieu, sino con un contenido más amplio y profundo.

El Juez hoy no es la boca de la Ley, porque la interpretación y 
aplicación de la norma no es operación mecánica y simple sino compleja y comprometida en la medida que el Ordenamiento Jurídico tiene lagunas y tiene contradicciones. Lagunas y contradicciones que tienen que ser superadas en la práctica judicial mediante la búsqueda de los principios a que la norma jurídica responda y que deben resolver el conflicto que el pleito objetiva. El art. 1 párrafo sexto del Código Civil lo reconoce expresamente al decir que la Jurisprudencia complementará el Ordenamiento Jurídico. Sólo se complementa lo que no está completo.

El Juez no es creador de la norma atribuida, que le corresponde al Parlamento. El Juez es -debe ser-creador de justicia en la sentencia y por tanto un agente de pacificación del conflicto.

Es, ciertamente, el poder judicial un poder muy especial: es un poder disperso, repartido en toda España, cada Juez es en sí mismo el titular de dicho poder en el ámbito de su competencia objetiva y territorial, es un poder independiente, como garantía de la imparcialidad de su decisión, que la hace susceptible de aceptación social, es un poder transparente sin magias ni oscurantismos. El Juez es ante todo un razonador que a la vista de las pruebas y desde la esencial contradicción que define todo pleito, con dos partes opuestas, busca la solución justa mediante la aplicación de la norma adecuada en la interpretación correcta. Es, finalmente, un poder responsable: responsabilidad que se verifica en un triple aspecto: a) responsabilidad jurídica en los órdenes civil, penal o disciplinario, como el resto de las autoridades públicas, b) control jurisdiccional a través de los recursos, c) control social difuso si se quiere pero no inexistente mediante la crítica de las resoluciones judiciales, tanto más importante cuanto mayor sea la dimensión social de la decisión. Todos tenemos la vivencia de noticiarios plagados de noticias y comentarios judiciales.

Existe también un control político, en cuanto poder del Estado y por tanto no en relación a esta o aquella resolución, sino en cuanto respuesta global y aceptación social de la misma. Es el control que se le exige al Consejo General del Poder Judicial ejercido por el Parlamento, titular de toda la soberanía y concretada en las comparecencias que ante él efectúan los Vocales y el Presidente del Consejo.

Finalmente, podemos hablar de la Administración de Justicia como servicio público, como el servicio público de la Justicia.

Desde esta perspectiva, el poder judicial aparece como el conjunto de órganos estatales que dirimen los diversos conflictos que se le plantean. Dicho de otro modo, es el sistema institucional mediador del Estado de Derecho, integrado por un conjunto de órganos que atiende a aquella finalidad mediadora, pacificadora y garantizadora de los derechos de los ciudadanos. 
De igual suerte que los ciudadanos tienen derecho a que se les preste el servicio público de sanidad o el de educación, también lo tienen a que les sea satisfecha su necesidad de seguridad jurídica y solución de los conflictos intersubjetivos en los que puedan estar involucrados, y para ello existen un conjunto de órganos debidamente estructurados y especializados que mediante protocolos previamente determinados, y con el correspondiente soporte burocrático, se dedican a la satisfacción de aquellas necesidades.

Podríamos intentar una definición totalizadora de la Justicia que englobase las tres perspectivas citadas diciendo, con José Jiménez Villarejo", que "la Justicia es un servicio público al que tienen derecho los ciudadanos, que se administra por miembros de un poder del Estado, mediante cuya actuación se pretende realizar en la vida social un valor ético que ha sido definido por la Nación Española como uno de los valores supremos del ordenamiento jurídico".

Desde esta acepción que se comenta, verificamos que, en la Administración de Justicia, se dan todas las notas que caracterizan el servicio público.

En efecto, existe una red estructurada, sistemáticamente constituida por la planta judicial de Juzgados y Tribunales, una oferta de prestaciones de interés público, constituida por las decisiones judiciales que ponen fin a los pleitos, siendo tales prestaciones ofrecidas de forma continuada, uniforme e igual para todos, de forma gratuita -las costas judiciales son sólo los honorarios de abogado y derechos del procurador-y universal a todos los ciudadanos, $\mathrm{y}$, finalmente, el servicio público que se presta tiene una vocación de proximidad al ciudadano, transparencia, eficacia y rapidez.

Resulta al respecto oportuna la reflexión de que la Justicia, por el simple hecho de ser demorada, deja de ser justa. Con Enrique Ruiz Vadillo 2 podemos afirmar que "una sentencia en el fondo justa, perfecta, técnica e, incluso, humanamente, no es nada si le falta la adecuación con el tiempo".

Como núcleo del servicio, podemos distinguir:

a) Un órgano de decisión, constituido exclusivamente por el juez, único titular del Poder Judicial, juez que acumula a esa naturaleza de Poder del Estado, que le da al servicio una naturaleza especial, la de

José Jiménez Villarejo: Justicia, ética y derecho. En el volumen de estudios en homenaje a Enrique Ruiz Vadillo. Colex 1999, pág. 333 y siguientes.

2 Enrique Ruiz Vadillo: Exigencias Constitucionales en el proceso penal como garantía de la realización de la justicia. La grandeza del Derecho Penal. Discurso leído en el acto de su recepción como académico electo de la Real Academia de Jurisprudencia y Legislación. Madrid 1996, pág. 248. 


\section{funcionario público.}

b) Un órgano de ejecución que también se residencia en el juez. Recordemos que el art. $117-3^{\circ}$ de la Constitución Española nos dice que corresponde "exclusivamente" a los Juzgados y Tribunales el ejercicio de la potestad jurisdiccional "juzgando y haciendo ejecutar lo juzgado".

c) Especialización del servicio, constituido por los diversos órdenes jurisdiccionales y, dentro de ellos, por las especialidades existentes. A modo de ejemplo, podemos citar los juzgados de familia, dentro del orden civil, y los juzgados de menores y los de vigilancia penitenciaria dentro del orden penal.

d) Un protocolo de actuación, adecuado a cada orden jurisdiccional -civil, penal, social y contencioso-administrativo- constituido por las leyes de procedimiento que determinan la actividad del juez y de las partes, regula la prueba y en definitiva constituye el marco dentro del cual se estudia la cuestión debatida y se resuelve.

e) Unos medios materiales constituidos por todo el aparataje necesario e imprescindible para la prestación del servicio: edificios, material de oficina, sistema informático, etc.

f) Medios personales, constituidos por todas aquellas personas que prestan su auxilio y colaboración a los jueces y tribunales. A ellos se refiere el Libro VI de la Ley Orgánica del Poder Judicial, arts. 454 a 508, citándose expresamente a los Secretarios Judiciales, Médicos Forenses, Oficiales, Auxiliares y Agentes. Se trata de una lista abierta porque también se especifica que integrarán tal concepto de personal al servicio de la Administración de Justicia “...los miembros de los cuerpos que puedan crearse por Ley...", y, más específicamente, el art. 508 se refiere a "...los profesionales $y$ expertos que sean permanente u ocasionalmente necesarios para auxiliar... a la Administración de Justicia...", los que, caso de tratarse de funcionarios de las Administraciones Públicas, actuarán bajo la dependencia funcional del Tribunal o Juzgado respectivo.

La unión de los medios materiales y personales integra la llamada oficina judicial, que resulta imprescindible para que el Juez pueda realizar su función. Se trata de medios puestos a disposición de él por las Administraciones estatal o autónoma, aspecto de la mayor importancia desde un doble punto de vista:

a) Existe la obligación de facilitar al Poder Judicial los medios materiales y personales sin los cuales no podemos hablar de servicio público.

b) Tales medios pueden ser facilitados por la Administración Central y 
también por las Comunidades Autónomas, lo que permite que éstas tengan un protagonismo relevante en la calidad del servicio, por su mayor proximidad y sensibilidad, e incluso puedan completar los medios personales, facilitando y financiando la existencia de servicios de naturaleza asistencial que cada vez se ofrecen como más imprescindibles para mejorar la calidad del servicio, hacerlo más eficaz y más humanizado en la medida que pueden facilitar unos datos de indudable valor que, si no es a través de estos servicios asistenciales, no llegarían a conocimiento judicial. Piénsese, por ejemplo, en los asistentes sociales, psicólogos y criminólogos y la importancia de los datos que pueden facilitar a los Jueces en casos de crisis matrimoniales, drogodelincuentes o violencia familiar, datos que pueden orientar muy eficazmente el sentido de la decisión judicial que deba adoptarse.

Más adelante, se analizará esta cuestión que en definitiva incide directamente en el tema de la ponencia, pero ya adelantamos la necesidad de profundizar en esta línea que debe producir una efectiva interrelación entre el sistema judicial y los sistemas asistenciales facilitando abordajes interdisciplinarios en sintonía con la naturaleza plural que tienen muchos de los problemas que se someten a la decisión judicial, lo que resulta especialmente relevante en materia penal, donde, frecuentemente, la actividad delictiva no es sino la exteriorización de unas causas profundas que quedan extramuros del sistema de justicia penal pero que deben ser conocidos por éste para una mejor respuesta a aquel quehacer delictivo enjuiciado.

\section{EL DERECHO PENAL COMO INSTRUMENTO DE CON- TROL SOCIAL.}

El derecho penal constituye uno de los medios de control social existentes en la sociedad. Existen otros en la sociedad, tales como la familia, la escuela, la profesión, los grupos sociales, sin embargo, el Derecho Penal es cualitativamente diferente del resto de los citados. El derecho penal es un medio de control jurídico, altamente formalizado, que contiene el catálogo de acciones que se estiman contrarias a la convivencia y el derecho y dignidad de los ciudadanos.

El Código Penal es la relación de acciones convenientemente descritas -principio de legalidad-, que se estiman indeseables y por ello se les considera delictivas. Por ello, se describen y se determina la respuesta penal para quienes los cometan, lo que provoca una general amenaza para todos que consigue el fin de prevención general dirigido a toda la sociedad, además del efectivo castigo - prevención especial- 
para el concreto infractor: es tan importante este medio de control social que queda monopolizado por el Estado y efectuado por el Poder Judicial.

Nada parecido con aquellos otros medios de control social citados, que son informales y no jurídicos.

Precisamente por sus características de control formalizado, jurídico, monopolizado por el Estado y relativo a las acciones en las que el consenso social se ha traducido en su consideración de total rechazo a esas acciones, se trata del último recurso -ultima ratio- que tiene para defenderse la sociedad de los actos antisociales, es la última barrera de defensa, la retaguardia de la defensa de la conciencia y, por lo tanto, utilizable cuando los demás medios de control social, jurídicos o no, resultan insuficientes.

Por eso, al Código Penal, se le llama la constitución negativa, por oposición a la Constitución que contiene los derechos y garantías de los ciudadanos y el cuadro de valores que vertebra la vida en comunidad.

Este control formalizado y coactivo se impone a través del proceso que tiene por objeto la búsqueda de la verdad material, no a cualquier precio, sino sólo y exclusivamente desde el respeto a las garantías procesales propias de un estado de derecho y, por tanto, con proscripción de aquellos métodos de investigación que no respeten la dignidad humana; por eso, recordando la célebre polémica entre los jueces norteamericanos Cardozo y Holmes sobre qué debe prevalecer si las garantías o la certeza, hay que resolver el dilema -falso dilema desde la perspectiva del Estado de Derecho- a favor de las garantías.

El fin de este instrumento -el último- de control social altamente formalizado y de naturaleza jurídica es la sanción de las acciones estimadas delictivas e imputables a persona determinada.

Ciertamente la respuesta penal al delito es siempre de naturaleza punitiva, ya privativa de libertad, restrictiva de derechos o pecuniaria. Este fin esencial no se agota en sí mismo, sino que toda pena, singularmente las de prisión, por exigencia del art. $25-2^{\circ}$ de la Constitución Española, debe estar orientada hacia la reeducación y reinserción social.

Actualmente, sin desconocer la naturaleza de castigo que tiene la pena, su finalidad no se agota en ese aspecto retributivo, sino que al mismo tiempo debe propiciarse un reencuentro del agresor con la sociedad en general, incluida la víctima, que permita una efectiva reconciliación y, con ella, un deseo de abandono de la actividad delictiva y la reintegración social del condenado sin olvidar la de la víctima que, en muchas ocasiones - piénsese en los delitos contra la libertad sexual, los de terrorismo o violencia de género- también necesita reconciliarse 
consigo misma mediante su re-personalización.

Se preguntaba Carnelutti sobre cuál fuera la causa del delito y se contestaba diciendo que en los delitos culposos era la falta de amor y, en los dolosos, el odio, es decir, la negación del amor. Por eso, sólo se puede y se debe juzgar desde el amor, como recordaba Nitchte. Amor que es aplicación humanizadora del derecho penal para el delincuente y también para ese gran olvidado que ha sido la víctima.

\section{LA PERSONA, CENTRO DEL SISTEMA DE JUSTICIA PE- NAL.}

Para las escuelas penales clásicas, pecando de un exceso de dogmatismo, configuraron el derecho penal como una relación exclusiva entre el Estado y el infractor, concebido éste no en su insustituible corporeidad e individualidad, sino en su visión abstracta de "infractor" del ordenamiento jurídico y, por tanto, como sujeto pasivo de la reacción estatal. No por coincidencia, esta disciplina se denomina "derecho penal", en explícita referencia al estudio de la pena, que, junto con el del delito, constituía el binomio que agotaba todo el estudio de la materia. Es en esta concepción donde se acuña y tiene sentido el temible brocardo "Fiat iustitia pereat mundus".

Primero fue la escuela positivista italiana -Lombroso, Garofaloy y Ferri-, con su aproximación al delincuente de carne y hueso, la que convirtió aquella dualidad delito-pena en una relación triangular, al introducir, como tercer elemento de estudio, la persona del delincuente de carne y hueso, rompiendo aquel binomio estático y esencialista por una relación triangular claramente existencialista.

Los delitos no existen, son una abstracción, existen personas que delinquen, existe el delincuente concreto, no como abstracción. Posteriormente, tras la Segunda Guerra Mundial, de manos de la Sociedad Mundial de Victimología comienza el descubrimiento de la víctima y su protagonismo en el drama penal, concretándose la sensibilización en esta materia en la Recomendación del Consejo de Europa de 28 de junio de 1985 sobre la posición de la víctima en el campo del Derecho Penal y procesado penal, pero queda mucho camino por recorrer. Como simple botón de muestra, recordemos que la Memoria de la Fiscalía General del Estado de 1996 decía que "...probablemente se ha avanzado mucho en la protección de los derechos de los inculpados. Pero este posible avance sobre la legislación anterior no ha sido seguido con el correlativo de los derechos de las víctimas..."."3 
Prácticamente, ninguno de los textos fundamentales internacionales o nacionales definitorios del delito han hecho la menor referencia a la víctima hasta hace pocos años. En España, a título de ejemplo, podemos citar la Ley 35/95 de 11 de diciembre de ayuda y asistencia a las víctimas de delitos violentos y contra la libertad sexual, seguida por la Ley $32 / 99$ de 8 de octubre de Solidaridad con las víctimas del Terrorismo.

Hoy día, el sistema penal se concibe como una relación entre el Estado, el agresor y la víctima, reconociendo un efectivo protagonismo a tres bandas. El delito ya no es abstracción esencial, sino que se reconoce como situación que surge en un contexto determinado, que tiene una pluralidad de perfiles que es preciso reconocer y conocer para su abordaje.

Por decirlo, en palabras de Antonio García Pablos ${ }^{4}$, el crimen no es un tumor, ni una epidemia, sino un doloso problema interpersonal y comunitario. Una realidad próxima, cotidiana, casi doméstica: un problema "de" la comunidad que nace "en" la comunidad y ha de resolverse "por "ésta. Un "problema social", en definitiva, con todo lo que tal caracterización implica en orden a su diagnóstico y tratamiento.

Hoy la justicia penal ya no debe mantenerse aunque perezca el mundo, sino que encuentra su justificación en el mantenimiento de éste. Fiat iustitia ne pereat mundus.

Como advierte Hassemer, ${ }^{5}$ será difícil que el Juez acierte en su decisión del caso concreto y que tengan éxito los programas de prevención del delito y resocialización del delincuente, si se carece de los conocimientos científicos más elementales sobre el problema criminal.

Son esos conocimientos los que deben serle suministrados al sistema judicial por los correspondientes especialistas, porque, obviamente, los auxiliares ordinarios del Juez, los elementos personales que conforman la Oficina Judicial, a la que me he referido anteriormente, ni están diseñados para esta misión, ni capacitados para ello. Hacen falta otros especialistas.

\section{LAS LIMITACIONES DE LA RESPUESTA PENAL.}

Consecuencia directa de la concepción del delito como una situación es que la respuesta penal, partiendo de su legitimidad en cuanto sancionadora, resulta insuficiente para resolver el tema de la delin-

4 Antonio García-Pablos: La prevención del delito en un Estado social y democrático de derecho. Estudios Penales y Criminológicos XV. Universidad de Santiago, 1990.

5 Citado por Antonio García-Pablos: Criminología. Tirant Lo Blanch, 1992, pág. 87. 
cuencia. Precisamente la legitimidad de la respuesta, casi siempre carcelaria, pues la cárcel sigue siendo la columna vertebral del sistema, vendrá incrementada en la medida que existan otras respuestas que respondan más inteligentemente a la delincuencia, pues si esta está provocada por una causa interna, de la que la actividad delictiva es sólo su consecuencia, pobres resultados se extraerán de sancionar exclusivamente la consecuencia si dejamos intacta la causa que la provoca.

Ejemplo paradigmático de lo que se dice lo encontramos en las situaciones de drogodelincuencia, es decir, la de personas que delinquen motivadas por la necesidad de consumir droga, comprándolas en el mercado clandestino. Es un típico caso de delincuencia funcional en general dirigida a delitos contra la propiedad. Si la única respuesta es la carcelaria, lo único que se habrá conseguido, en el mejor de los casos, es una inactividad delictiva coincidente con su estancia en prisión.

Parece claro, desde la perspectiva de una política criminal tendente a rebajar las cifras de la delincuencia, que se facilite, siempre en clave de voluntariedad, la posibilidad de un abandono del consumo de drogas. Si se consigue, no sólo se habrá apartado a la persona de la causa que generaba su actividad delictiva, sino que se habrá dado un cabal cumplimiento a la vocación de reinserción social al que deben responder las penas de prisión.

Evidentemente este proceso de repersonalización debe efectuarse en un ambiente extra-penitenciario, porque es difícil aprender a ser libre responsablemente en un entorno de no libertad. Por eso puede afirmarse que las alternativas a la prisión son alternativas a la delincuencia.

El fracaso de la prisión, respuesta que paradójicamente sigue siendo necesaria. La Exposición de Motivos de la Ley General Penitenciaria $1 / 79$ de 26 de Septiembre reconoce que "...las prisiones son un mal necesario y... previsiblemente habrá de seguirlo siendo por mucho tiempo...", está acreditado por las altas cifras de reincidencia.

Por eso, en clara ruptura con los precedentes representados por la Ley de Vagos y Maleantes de 1933 y la Ley de Peligrosidad y rehabilitación social de 1970, el vigente Código Penal aprobado por la L.O. 10/95 de 23 de noviembre incluye en el título IV una precisa regulación de las medidas de seguridad que puedan imponerse, con absoluto respeto al principio de legalidad y al derecho penal del acto concreto enjuiciado, eliminando los “tipos criminológicos de autor".

Presupuestos para la aplicación de las medidas de seguridad son tres:

a) Según el art. 1-2 , sólo podrán aplicarse cuando concurran los pre- 
supuestos establecidos en la Ley.

b) Su fundamento está en una peligrosidad ya exteriorizada en el delito cometido, es decir, postdelictual, sin que quepa la peligrosidad antisocial predelictual. El art. 95 que desarrolla el 6, determina un doble presupuesto para su adopción: $1^{\circ}$ que el sujeto haya cometido un hecho delictivo y $2^{\circ}$ que el pronóstico del futuro comportamiento revele la probabilidad de la comisión de nuevos delitos.

c) Las personas que pueden ser sometidas a medidas de seguridad son las definidas en los artículos 101 a 104 que en síntesis se refieren a dos grupos: los exentos de responsabilidad penal por falta de imputabilidad, ya sea por enfermedad mental, intoxicación plena alcohólica o de drogas o alteración de la percepción, pero que han cometido un delito, existiendo pronóstico de nuevos delitos, y, en segundo lugar, en esos mismos supuestos pero cuando la responsabilidad criminal, y por tanto la imputabilidad están limitadas, no acumuladas y se haya aplicado en consecuencia una eximente incompleta.

Por su especial incidencia en el tema de la ponencia me referiré en concreto a los supuestos de personas que delinquen por su adicción al consumo de drogas tóxicas.

El anterior Código Penal desconoció el valor de la droga como factor criminógeno. Fue una creación judicial la que paulatinamente valoró dicha situación cuando se acreditaba la adicción en el acusado con una doble consecuencia:

a) Estimando una disminución de la imputabilidad severa o leve, o incluso una anulación total.

b) Acordando, junto con la atenuación de la pena, una medida de seguridad tendente a facilitar la desintoxicación del sujeto. La primera sentencia de la Sala Segunda del Tribunal Supremo, confirmatoria de la dictada en instancia, que reconoció el valor de la toxicomanía y su incidencia en la acción delictiva enjuiciada, fue la de 16 de septiembre de 1982.

El legislador tardó siete años en reconocer la relación droga-delito y propiciar como respuesta más inteligente distinta a la pena de prisión, bien que lo permitiera en términos mucho más cicateros que los que la práctica judicial -más de setenta sentencias de la Sala Segunda entre los años 1983 a 1988- ya había consolidado. Véase al respecto el art. 93 bis del anterior Código Penal introducido por la L.O. 1/88 de 24 de marzo.

En el Código actual, la figura del drogodelincuente está expresamente reconocida -art. $20-2^{\circ} ; 21-1^{\circ}$ y $2^{\circ} ; 87$ y $104-$, y sin perjuicio de reconocer un avance en relación al Código Penal anterior, hay que 
recordar que el ámbito de aplicación de las medidas de seguridad alternativas a la prisión ha sido ampliado por la Sala Segunda del Tribunal Supremo en relación al marco legal dibujado en el Código.

A partir de la STS de 11 de abril de 2000, se efectúa una nueva lectura del art. 104 del vigente Código Penal y, frente a la literalidad del precepto, se reconoció que en los casos de drogodependencia con moderada disminución de las facultades intelectivas o volitivas del sujeto también quedaba abierta la posibilidad de adoptar medidas de seguridad de naturaleza desintoxicadora siempre que fuesen aceptadas por el sujeto.

En consecuencia la respuesta judicial a la delincuencia funcional derivada del consumo de drogas es, en palabras de la STS 650/2000 de 14 de abril:

a) Eximente completa en casos de extraordinaria dependencia con total anulación de sus facultades intelecto-volitivas.

b) Eximente incompleta, en casos de grave déficit sin llegar a la anulación.

c) Atenuante en casos de menor intensidad.

En los tres casos cabe la adopción de las medidas de seguridad previas y sustitutivas de la prisión en el Código Penal, de acuerdo con la regulación que allí se contiene y que no paso a detallar por no desbordar el contenido de la ponencia.

A los efectos que nos interesan, lo relevante es que estas medidas de seguridad, que incluso pueden ser adoptadas después de dictada la sentencia, como recuerda la STS 232/2000 de 18 de febrero y expresamente prevé el art. 105, exigen necesariamente un contacto entre el sistema judicial y el asistencial que de hecho gestiona, bien en régimen ambulatorio, de comunidad terapéutica o mixto, los procesos de desintoxicación.

Ciertamente que no se puede ignorar la existencia, hoy en día, de una oferta plural de programas para toxicómanos dentro del recinto carcelario, que van desde los propiamente deshabituados hasta los de mantenimiento como los tratamientos de metadona y de intercambio de jeringuillas. En todo caso, cabrá convenir que el contexto penitenciario no es, ni con mucho, el más idóneo para iniciar un proceso de desintoxicación y de paralela rehabilitación. Todavía en la Memoria de la Fiscalía General del Estado del año 1987 se afirma que las cárceles son nidos de delincuencia violenta.

Precisamente la realidad de los programas que se llevan a cabo en las cárceles sólo se justifican, como programas de mínimos, para aquellas personas que no puedan tener acceso a los programas extrapenitenciarios. 
Es precisamente en relación a los programas extrapenitenciarios, auténtica alternativa a la prisión, donde se precisa ese diálogo entre los sistemas judicial y asistencial.

De un lado, es un dato de experiencia que el sistema de justicia penal no ofrece posibilidades reales de reintegración social. Las cárceles no rehabilitan.

De otro lado, es preciso salvaguardar la vocación de reinserción social a que están llamadas las penas de prisión. Ello sólo es posible mediante la colaboración de las instituciones públicas o privadas, éstas convenientemente homologadas, que ofrezcan otras respuestas no prisonizadas al hecho delincuencial, singularmente a la delincuencia funcional derivada del consumo de drogas.

Urge articular este diálogo entre el sistema judicial y el asistencial si queremos ir a una justicia de y para la persona, y no sólo una justicia de y para los delitos. El reconocimiento de la interdisciplinariedad del tema exige una apertura del sistema judicial a la sociedad, aplicando al máximo las posibilidades legales, ya ampliadas, como se ha visto por la propia doctrina jurisprudencial expuesta, lo que debe llevar a una cierta relativización de la respuesta de prisión que puede llegar a ser subsidiaria en los casos de drogodelincuencia que estudiamos.

Precisa y paradójicamente, la legitimación de la respuesta carcelaria será directamente proporcional a la existencia de otras respuestas extrapenitenciarias.

Recordemos la reflexión de que el delito, como fracaso de la convivencia, surge en una sociedad, y es esa sociedad la que tiene que asumir un cierto protagonismo, la delincuencia no es algo que afecte o concierna exclusivamente a jueces y policías.

¿Qué debe pedir el sistema penal al sistema asistencial?

a) Que exista, es decir, que tanto las instituciones públicas como las entidades privadas tengan proyectos o programas de actuación de los que puedan beneficiarse personas condenadas. En caso de toxicómanos delincuentes, que existan tales programas de desintoxicación y de rehabilitación.

b) Una leal colaboración, recíproca en los dos sentidos. Lealtad fundada en el reconocimiento de las propias exigencias de cada uno de los sistemas, buscando la zona de encuentro.

c) Caso de tratarse de entidades privadas, que éstas estén convenientemente homologadas por la Administración, lo que es importante en materia tan sensible y delicada como son las comunidades terapéuticas de desintoxicación, y control administrativo doblemente justificado, por ser normal que tengan en todo o parte una financiación con fondos públicos. 
d) Un seguimiento judicial de los tratamientos y de la respuesta, y en este punto es necesario decir que el sistema judicial no debe incidir en el contenido de los tratamientos -de ahí la exigencia de homologación pública que acabamos de citar-.

e) Diálogo directo e inmediación evitando toda burocratización inútil, retardataria y distanciadora.

¿Qué debe ofrecer el sistema penal al asistencial?

a) Reconocimiento de la primacía de la reinserción y del tratamiento, frente a la naturaleza meramente custodial de la prisión.

b) No prisonizar el tratamiento si se trata de ofrecer una alternativa a la prisión, la medida o el programa de desintoxicación, ya sea ambulatorio o en régimen de comunidad terapéutica -singularmente en ésta-no debe ser tratado judicialmente como un anexo a la prisión. Reconocer el propio ámbito autónomo en el que se desarrolla la medida, sin confundir el programa con el recurso. El programa tiene o puede tener una unidad interna que se desarrolla en la utilización sucesiva de varios recursos. Es frecuente que un programa de desintoxicación se integre por la utilización de diversos recursos: comunidad terapéutica, pisos, tratamiento ambulatorio, etc. Es preciso respetar esta estructura y reinterpretar, desde esta realidad, el término de internamiento que se utiliza en el Código Penal.

c) Colaboración leal y recíproca así como diálogo fluido e inmediación sin burocratización inútil en los mismos términos que se solicita del sistema asistencial.

De lo expuesto, se deriva, a mi juicio, una conclusión:

No hay oposición entre los fines asistenciales y los que tiende el sistema judicial. No debe haber lugar a enfrentamientos ni a desconfianza. Precisamente el sistema judicial estará más imbricado en la Sociedad en la medida que exista una red fértil de intercomunicación entre aquél y ésta.

\section{DERECHO PENAL, CRIMINOLOGÍA Y POLÍTICA CRIMI- NAL.}

Como afirma García-Pablos ${ }^{6}$, superados los momentos de enfrentamiento entre la Criminología y el Derecho Penal, hoy se impone un modelo integrado impuesto por la necesidad de un método interdisciplinario y por la unidad del saber científico. La dogmática penal se vuelca cada vez más hacia la realidad, y las ciencias empíricas ofrecen 
su colaboración al legislador para resolver los problemas sociales reales.

El Derecho Penal es una ciencia jurídica, cultural y normativa, es la que estudia el delito en abstracto, los presupuestos de su persecución y sus consecuencias. La Criminología se enfrenta al delito como fenómeno real y se sirve de métodos empíricos para estudiarlo.

Haciendo puente entre ambas, la Política criminal es la disciplina que suministra a los poderes públicos las opciones científicas concretas más adecuadas para el eficaz control del delito.

Por ello, Criminología, Política Criminal y Derecho Penal son los tres pilares del sistema de ciencias criminales inseparables e interdependientes.

Una respuesta científica al crimen -continúa el autor citado- exige un proceso lógico que consta de tres fases:

a) La fase explicativa que le corresponde a la Criminología, mediante la aportación de los conocimientos verificados empíricamente sobre el hecho delictivo.

b) La fase decisional corresponde a transformar esos datos empíricos en opciones y programas científicos y trasladarlos a los poderes públicos a fin de que propongan las normativas correspondientes.

c) Finalmente el Derecho Penal es la objetivación de la decisión tomada, que, por ello, ya es operativa. Es decir, el Derecho Penal es la concreción de la opción adoptada en base al estudio criminológico efectuado.

El Derecho Penal marca la respuesta ante el crimen y los límites de dicha respuesta, por eso el Derecho Penal, como "Carta Magna del delincuente", en la conocida frase de Von Listz, marca no sólo los límites a la libertad individual, sino también los límites a la intervención estatal.

En este planteamiento, el sistema de justicia penal se nos debe presentar como abierto a la Sociedad, no un mundo aparte, sino como parte de nuestro mundo y, por eso, su respuesta -ya lo hemos vistolimitada y necesitada de otras respuestas procedentes de la Sociedad.

Como decía Jeffery "más leyes, más penas, más policías, más jueces, más cárceles, significa más presos, pero no necesariamente menos delitos". Este sistema reactivo, por otra parte tan sensible a oportunistas discursos políticos jaleados por los medios de comunicación, tiene acreditado su fracaso. La eficaz prevención del crimen no depende tanto de la mayor efectividad del control penal como de la

Jeffery, C.P.: "Criminology as an interdisciplinary behavioral science", cn Criminology 16.2 - 1978, págs. 149 a 169. 
integración de éste en la sociedad y de su sintonía con otros sistemas de control social informal.

Una Ley no es más eficaz por incrementar la respuesta punitiva.

Nuevamente la exigencia de una apertura y conexión a la sociedad, y paralelamente de una vertebración de la respuesta penal con la asistencial. Ya hay experiencias al respecto y todas positivas como veremos seguidamente.

\section{EXPERIENCIAS DE COOPERACIÓN ENTRE LOS SISTE- MAS JUDICIAL Y ASISTENCIAL EN EL CAMPO DE LA VIOLENCIA.}

\subsection{Los Servicios de orientación y asistencia al detenido.}

En algunas sedes judiciales, cada vez en mayor número, existe este servicio atendido por trabajadores sociales, psicólogos y criminólogos, fundamentalmente, que prestan su ayuda a los detenidos en el Juzgado de Instrucción desde el mismo momento de la puesta a disposición judicial y siempre en clave de voluntariedad. Si el detenido lo desea, se entrevista con ellos, quienes efectúan un informe del interesado de naturaleza psico-social incluyendo datos que pueden ir desde el consumo de drogas, información sobre central de desintoxicación, situación personal y laboral y contexto familiar.

Datos todos de la mayor importancia a la hora, por ejemplo, de que el Juez pueda tenerlos en cuenta en orden a su situación familiar.

Incluso, por mi propia experiencia profesional, puedo decir que tales servicios podrían prestar también una función de enlace entre el sistema judicial y las alternativas a la prisión que puedan adoptarse en la sentencia en caso de drogo-delincuencia, ya que, en general, pueden gestionar el ingreso por cuenta de los interesados en los Programas correspondientes, dando cuenta a los Tribunales de la respuesta al tratamiento, con quienes mantendrían una estrecha relación, informes que se introducirían en el proceso penal, bien a través de los escritos correspondientes como, principalmente, mediante comparecencia en el Juicio Oral dando cuenta al Tribunal sentenciador de la real situación de la persona en relación a las drogas, y pronóstico de futuro.

En general, estos profesionales que atienden el Servicio suelen ser contratados por la Comunidad Autónoma, norma respectiva, y están ubicados en el propio edificio judicial, y, en la medida que ponen a disposición del sistema judicial sus conocimientos, no cabe duda que deben ser considerados como personal al servicio de la Administra- 
ción de Justicia que actúan funcionalmente bajo la dependencia del Juzgado o Tribunal al que estarían adscritos -generalmente al Juzgado Decano a la Audiencia Provincial-, de acuerdo con el art. 508 de la Ley Orgánica del Poder Judicial que tiene grandes posibilidades de utilización que es preciso aprovechar, aunque obviamente pueden dar su servicio a todos los órganos judiciales del orden penal, bien del partido judicial o de la parte de la provincia o de toda ella, según los casos y según se prevea en el reglamento de su implantación.

Por propia experiencia profesional conozco a fondo los servicios de este tipo existentes en el País Vasco, singularmente el de Bilbao y puedo declarar lo extraordinariamente beneficiosos que resultan para una justicia más humanizada y para una utilización óptima de las posibilidades legales, posibilitando efectivamente que el Derecho, singularmente el penal, no quede reducido al monopolio de la fuerza ni al sólo empleo de la misma.

Como botón de muestra, me referiré al estudio publicado por el departamento de Justicia del Gobierno Vasco y dirigido por el Catedrático de Sociología de la Universidad de Deusto Javier Elzo. ${ }^{8}$

Se escogió una muestra de 231 personas a las que en los años 1991-1992 se les aplicó medida de ingreso en comunidad terapéutica -fueron ocho los centros escogidos en todo Euskadi-como alternativa a la pena de prisión que pudiera corresponderles por el delito cometido. Se trataba de reencontrarse con esas personas cinco años después para verificar cuál era la situación.

En síntesis los resultados fueron los siguientes:

De las 231 personas no se pudieron localizar 68, habían fallecido nueve y, de los 154 restantes, seguían consumiendo 8 , se encontraban en situación dudosa -stand by- 33 y habían abandonado el consumo de drogas 113 personas.

Los datos hablan por sí solos.

¿Hubiera conseguido el sistema de justicia penal, sólo con la respuesta carcelaria, estos resultados?

Reiteramos lo ya dicho de que la alternativa a la prisión es en realidad una alternativa a la delincuencia; pero ello sólo es posible mediante la leal e intensa colaboración entre el sistema de justicia y el asistencial.

s Alternativas Terapéuticas a la prisión en delincuentes toxicómanos. Un análisis de historias de vida. Departamento de Justicia Servicio Central de Publicaciones del Gobierno Vasco. Vitoria-Gasteiz, 1996. 


\subsection{Los servicios de asistencia y protección a la víctima.}

Resultan de una urgencia inaplazable. La reciente Carta de Derechos del Ciudadano ante la Justicia, elaborada por un grupo de trabajo constituido en el seno de la Comisión de seguimiento del Pacto de Estado para la Reforma de la Justicia, firmado el 28 de mayo de 2001, reconoce en el apartado II, significativamente rubricado "Una justicia que protege a los más débiles", la necesidad de potenciar las oficinas de atención a la víctima.

La víctima, como ya se ha dicho, y ahora se reitera, ha sido, y en gran parte sigue siendo, la gran olvidada del proceso penal, a pesar de que, incluso desde una perspectiva exclusivamente penal, la víctima tiene un innegable protagonismo desde el inicio de la investigación judicial, es ella la que pone en conocimiento de la policía o de la justicia la comisión de un hecho delictivo y, al mismo tiempo, en cuanto sujeto pasivo de la acción criminal es un instrumento decisivo de la investigación del hecho e identificación del delincuente.

Es fuente de prueba y prueba en sí misma en todo proceso, pero singularmente en aquéllos que se cometen en un escenario sólo animado por el agresor y la víctima, como ocurre por ejemplo en las agresiones sexuales.

Pero, además, la víctima es la primera lesionada con la acción criminal y su existencia patentiza el fracaso de la política de seguridad e indemnidad de los ciudadanos que corresponde al Estado.

No obstante, esta privilegiada situación ha sido tratada por el sistema de justicia penal con un total olvido; conviene recordar que no siempre fue así. La víctima disfrutó de su máximo protagonismo, ${ }^{9}$ verdadera "edad de oro", durante la justicia primitiva de naturaleza privada, después neutralizado por el actual sistema moderno de respuesta institucional caracterizado por una aplicación garantista de la Ley y una intervención serena, objetiva y desapasionada, pero que produjo el efecto perverso, y no consecuencia necesaria, de la dramática postración de la víctima por una exclusiva atención a los aspectos públicos del delito, más constatable en los sistemas jurídicos tributarios del Derecho Romano que en los de origen anglosajón.

Éstos históricamente supieron compaginar los intereses públicos y privados que se dan en cada delito, reconociendo un espacio propio a la víctima a través de instituciones como la mediación y los programas de reparación o la víctima que afortunadamente se están extendiendo en

9 Antonio García Pablos: "El redescubrimiento de la víctima. Victimización secundaria y programas de reparación del daño. La denominada victimización terciaria", En Victimología. Conscjo General del Poder Judicial, 1993, págs. 287 a 320. 
todos los sistemas jurídicos.

Frente a un modelo de justicia penal resolutivo, concretado en la pena como única respuesta a la delincuencia, hay que ir a un sistema de justicia conmutativo delimitado por el propio sistema judicial, el agresor y la víctima.

La víctima no reclama compasión, sino respeto a sus derechos y, en ocasiones, le puede ser suficiente una simple, pero sentida, reparación emocional por parte del agresor. No siempre hay que pensar en reparaciones en clave económica, y cuando éstas sean necesarias, dada la entidad de la agresión, y el causante de la misma carezca de bienes, como manifestación de un deber de solidaridad y de la quiebra del deber de protección que corresponde al Estado, deben arbitrarse programas de reparación del daño con cargo a fondos públicos.

A esta nueva filosofía responde la Ley $35 / 95$ de 11 de diciembre de ayuda a las víctimas de delitos violentos y contra la libertad sexual y su Reglamento de 23 de mayo de 1997, que fue seguida por la Ley 13/96, de 30 de diciembre, y el R.D. 1211/97, de 18 de julio, que aprueba el Reglamento de ayudas y reconocimientos a las víctimas de delitos de terrorismo.

Dentro del marco de los programas en favor de las víctimas, hay unos de asistencia inmediata, que por ser coetáneos a la propia agresión sufrida son de extraordinaria importancia.

Eje central de estos programas de asistencia inmediata son los servicios de asistencia a la víctima, que ofrecen servicios relacionados con las necesidades más imperiosas que tienen las víctimas de delitos, ya sean de naturaleza material, física o psicológica.

Ofrecen información sobre la forma de recabar ayudas económicas o psicológicas o auxilio inmediato -pisos de acogida, en caso de violencia de género-, sobre la asistencia jurídica o el devenir del proceso. Oficinas que o bien pueden estar situadas en los propios edificios judiciales, en una ubicación adecuada que impida el contacto o proximidad con los usuarios del Juzgado de Guardia, o bien fuera de tales edificios.

Normalmente gestionadas por profesionales y financiadas, al igual que los servicios de orientación y asistencia al detenido, por las Comunidades Autónomas, Ayuntamientos o asociaciones. Nuevamente el recordatorio de las posibilidades que ofrece el art. 508 de la Ley Orgánica del Poder Judicial, parece necesario.

Generalizar este servicio es tarea urgente si queremos poner fin a la continuada victimización de la víctima. Con acierto, se ha hablado de una victimización primaria, producida por el hecho delictivo: pero a ésta le sigue una victimización secundaria causada por el propio sis- 
tema policial-judicial, y derivada de la intervención de la víctima en el proceso en condiciones claramente deshumanizadoras que, incluso, puede llegar a ser más lamentable que la primaria porque es el propio sistema legal quien la provoca, porque se acumulan sobre los ya padecidos por la víctima y porque afectan al prestigio y aceptación social del sistema. Si éste maltrata a unos colaboradores indispensables del proceso, no nos podemos extrañar que el sistema sea mirado como extraño y dañino, del que hay que alejarse.

Todavía puede hablarse de una victimización terciaria consistente en el impacto futuro de la agresión y del trato procesal sufrido en la conducta posterior de la víctima.

También la víctima necesita una reinserción social desde el mismo momento de la agresión, y sin duda ese cometido debe venir de la mano de las oficinas de atención a la víctima en conexión con el propio sistema de justicia penal. Como afirma Esther Giménez Salinas, ${ }^{10}$ es un debate equivocado el pensar que mayores derechos a las víctimas van en perjuicio del delincuente, o que supone de alguna forma alimentar la venganza privada.

Dentro del campo de los servicios de ayuda a la víctima, debe hacerse una especial referencia a la violencia doméstica de la de género y a la respuesta interinstitucional que se está dando con una efectiva imbricación entre el sistema judicial y las Administraciones Públicas, tendentes a facilitar una pluralidad de respuestas todas integradas.

En efecto, en la violencia doméstica hay diversos ámbitos:

Un ámbito sanitario que exige una atención médica especializada y una actuación protocolizada.

Un ámbito psico-terapéutico de información a las víctimas y de asistencia inmediata.

Un ámbito policial donde la existencia de personal femenino y la confidencialidad en las oficinas policiales se una a una actuación igualmente protocolizada. Sobre todo, la denuncia inicial resulta imprescindible.

Un ámbito jurídico integrado por la asistencia jurídica, prioridad de los expedientes de justicia gratuita y turno especializado de letrado.

Un ámbito judicial del que podemos citar, como notas, la celeridad, la inmediación judicial, siempre necesaria y aquí imprescindible, y la coordinación de respuestas en el orden civil y penal y, personalmente, creo necesaria la especialización judicial en las grandes urbes. En Alicante se llevó a cabo esta experiencia -tres Juzgados en Alicante,

10 Esther Giménez Salinas: La mediación y la reparación. 1999 pág. 26. Centre d'Estudis Jurídics. Barcelona. 
Elche y Orihuela-, a la que se ha puesto fin, lamentablemente, sin razones convincentes, a mi juicio.

Esta pluralidad de escenarios no debe impedir el tratamiento coordinado y la protección integral de las víctimas de la violencia familiar, por ello, es preciso la firma de Convenios de Colaboración entre las instituciones implicadas.

A este respecto, se puede citar como modélico el Protocolo Internacional para la mejora en la atención a las mujeres y víctimas de maltrato doméstico y agresiones sexuales en el País Vasco de 25 de noviembre de 2000.

Protocolo firmado entre el Lehendakari del Gobierno Vasco, el Presidente del Tribunal Superior de Justicia del País Vasco, la Fiscalía del Tribunal Superior, los tres Diputados Generales de las tres Diputaciones Forales, el Consejo Vasco de la Abogacía, el Consejo Médico Vasco y la Asociación de Municipios.

\subsection{Los servicios de mediación familiar en casos de crisis matri- moniales.}

Si bien de una manera tangencial, puedan incluir tales servicios, como punto de encuentro entre el sistema judicial y los asistenciales, en la medida que con su intervención tratan de buscar un acuerdo posible entre aquellas parejas que quieren separarse o divorciarse, en temas económicos y paterno-filiales, desdramatizando el conflicto, y con una clara labor de prevención delictiva. En no pocos casos, la violencia de género o doméstico tiene su origen en una crisis de la pareja.

Desde otra perspectiva, estos servicios de mediación constituyen una manifestación de la función promocional del derecho que alienta e incentiva soluciones en clave de transacción/mediación con preferencia a la judicialización del conflicto matrimonial. ${ }^{11}$

\section{A MODO DE CONCLUSIÓN.}

Debemos recordar que uno de los Principios Rectores de Prevención del Crimen y de la Justicia Penal, acordados por el Comité de Prevención y Control del Crimen de Naciones Unidas en marzo de $1984^{12}$ es la consideración del sistema penal, no sólo como sistema de

1 Sobre la función promocional del Derecho, ver Norberto Bobbio: "La función promocional del Derecho en Contribución a la teoría del Derecho". Debate, 1989.

12 Manuel López Rey y Arroyo: Compendio de Criminologia y Política Criminal. Tecnos 1985, pág. 167 
control, intimidación y sanción, sino también de logro de un desarrollo más equitativo en todo aspecto, y a tal efecto -se afirma- se utilizarán tanto como sea factible las instituciones existentes fuera del sistema y la participación apropiada de la comunidad. Por ello, resulta inaplazable la generalización de los Servicios Asistenciales en conexión y al servicio del sistema de justicia penal y el protagonismo que las Comunidades Autónomas e instituciones públicas y privadas deben adquirir en esta materia.

Desde la consideración del delito como una situación o un fenómeno social, el delito y la criminalidad debe afrontarse como un problema, es el reverso de la convivencia social, que debe ser abordado desde un pluralismo metodológico, en el que el sistema penal y su reacción represiva es legítima a condición de que no sea la única ni la exclusiva.

Es necesaria la conexión del sistema penal con otras instancias, facilitando al sistema judicial respuestas no prisonizadas, por eso, en el campo específico de la disminución de la violencia de interrelación con los sistemas asistenciales, es necesaria para conseguir una efectiva reinserción social y una eliminación de la reincidencia, humanizando la respuesta penal tanto frente al agresor como a la víctima, camino indispensable para en un futuro utópico, si se quiere, pero utopía necesaria en la medida que ello nos permite el permanente cuestionamiento y búsqueda del valor justicia, dar a nuestra sociedad, como decía Radbruch $^{13}$, no un mejor derecho penal, sino algo mejor que el derecho penal. 